Check for updates

Cite this: Nanoscale Adv., 2019, 1, 4783

\title{
Surface group-modified MXene nano-flake doping of monolayer tungsten disulfides $\uparrow$
}

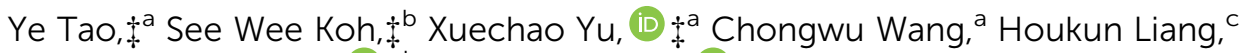 \\ Ying Zhang, ${ }^{c}$ Hong Li $\mathbb{D D}^{* b}$ and Qi Jie Wang (D)*a
}

Exciton/trion-involved optoelectronic properties have attracted exponential amount of attention for various applications ranging from optoelectronics, valleytronics to electronics. Herein, we report a new chemical (MXene) doping strategy to modulate the negative trion and neutral exciton for achieving high photoluminescence yield of atomically thin transition metal dichalcogenides, enabled by the regulation of carrier densities to promote electron-bound trion-to-exciton transition via charge transfer from TMDCs to MXene. As a proof of concept, the MXene nano-flake-doped tungsten disulfide is demonstrated to obtain an enhanced PL efficiency of up to five folds, which obviously exceeds the reported efficiency upon electrical and/or plasma doping strategies. The PL enhancement degree can also be modulated by tuning the corresponding surface functional groups of MXene nano-flakes, reflecting that the electron-withdrawing functional groups play a vital role in this charge transfer process. These findings offer promising clues to control the optoelectronic properties of TMDCs and expand the scope of the application of MXene nano-flakes, suggesting a possibility to construct a new heterostructure junction based on MXenes and TMDCs.

Received 22nd June 2019

Accepted 7th October 2019

DOI: 10.1039/c9na00395a

rsc.li/nanoscale-advances
Such strategies, including substitutional doping during growth, ${ }^{16}$ back gate or top liquid gate, ${ }^{20}$ vertical heterostructure and/or gas molecule adsorption, ${ }^{21,22}$ and band structure engineering, ${ }^{23}$ had been applied for manipulating the carrier concentrations in monolayer TMDCs. Nevertheless, the requirement for complicated and precise technological processes is the main hindrance to obtain the desired optoelectronic properties of monolayer TMDCs, which becomes a great limitation to the fundamental study of monolayer TMDCs. These daunting challenges stimulate the exploration of an alternative method to manipulate the optoelectronic properties of TMDCs. Chemical doping via the drop casting method has offered a foray into a promising and feasible method to modify the charge carrier densities of two-dimensional (2D) semiconductors. ${ }^{19,24}$ Till date, only few known chemicals have been utilized to control the carrier density in monolayer TMDCs to regulate their optoelectronic properties. ${ }^{17,22,25,26}$

Recently, a new type of 2D transition metal carbide (MXene) has been produced and synthesized from the MAX phase. ${ }^{27}$ The MAX phases are commonly represented by the chemical formula of $\mathrm{M}_{n+1} \mathrm{AX}_{n}$ (Fig. 1a), where $\mathrm{A}$ represents the main group element, $\mathrm{X}$ is $\mathrm{C}$ and/or $\mathrm{N}, \mathrm{M}$ is an early transition metal, and $n=$ 1,2 or $3 .^{28}$ Owing to the wet etching of the MAX phase in a fluoride-containing solution to remove A element and then delaminate the layers, the surface of the resulting MXene is always terminated by a mixture of functional groups of $-\mathrm{F},-\mathrm{O}$ and/or $-\mathrm{OH}$ with the corresponding chemical formula of $\mathbf{M}_{n+1}$ $\mathrm{X}_{n} \mathrm{~T}_{x}$ (Fig. 1b), where $\mathrm{T}$ represents the terminated functional group, and $x$ is the atomic percentage of terminated functional

\footnotetext{
${ }^{a}$ Centre for OptoElectronics and Biophotonics, School of Electrical and Electronic Avenue, 639798, Singapore

${ }^{b}$ School of Mechanical and Aerospace Engineering, Nanyang Technological University, 50 Nanyang Avenue, 639798, Singapore

${ }^{c}$ Singapore Institute of Manufacturing Technology, 71 Nanyang Drive, 638075, Singapore

$\dagger$ Electronic supplementary information (ESI) available. See DOI: 10.1039/c9na00395a

\$ These authors contributed equally to this work.
} 
group..$^{29}$ MXenes have attracted exponential attention in diverse fields including supercapacitance, ${ }^{30}$ electromagnetic interference (EMI) shielding, ${ }^{31}$ nonlinear photonics, ${ }^{32,33}$ Li-ion and other types of battery fabrication, ${ }^{34}$ photo-detection, ${ }^{35}$ energy storage, ${ }^{36}$ photothermal therapy ${ }^{37}$ as well as water purification ${ }^{38}$ because of their unique chemical and physical properties. In addition, the superior hydrophilicity of MXenes allows it to be easily dispersed in solution, making it a promising candidate for solution processing. Notably, according to the recent theoretical studies, MXenes were theoretically indicated for controlling the electronic density of TMDCs via tuning the surface functional group; nevertheless, this idea has not yet been experimentally explored..$^{39}$ In this study, as a proof of concept, we deposited the MXene solution onto 1-layer (1L) tungsten disulfide $\left(\mathrm{WS}_{2}\right)$ via the drop-casting method to tune exciton/trion-involved optoelectronic properties of $1 \mathrm{~L} \mathrm{WS}_{2}$ (Fig. 1c and d). MXene-decorated $\mathrm{WS}_{2}$ successfully achieved $\mathrm{a} \sim 5$-fold $\mathrm{PL}$ enhancement than the pristine $\mathrm{WS}_{2}$, which could have originated from the effective charge transfer from $\mathrm{WS}_{2}$ to MXenes induced by a strong electron-withdrawing effect of the attached surface functional group. We also reveal that this electron-withdrawing ability of MXenes can be well modulated by tuning its corresponding surface functional group via a postetch annealing method. This study not only extends the application area of MXenes, but also develops a simple and green strategy to achieve bright photoluminescence with high quantum yields in monolayer $\mathrm{WS}_{2}$.

\section{Experimental section}

\subsection{Synthesis of $\mathrm{Ti}_{3} \mathrm{C}_{2} \mathrm{~T}_{x}$ MXenes}

MAX phase $\mathrm{Ti}_{3} \mathrm{AlC}_{2}$ with a purity of $98 \%$ was purchased from Beijing Forsman Pte Ltd. $\mathrm{F}-\mathrm{Ti}_{3} \mathrm{C}_{2} \mathrm{~T}_{x}$ MXenes were made by etching MAX-phased $\mathrm{Ti}_{3} \mathrm{AlC}_{2}$ in $48 \% \mathrm{HF}$ at $60{ }^{\circ} \mathrm{C}$ for over $24 \mathrm{~h}$. After etching, the samples were washed and centrifuged (3500 $\mathrm{rpm}$ ) for $20 \mathrm{~min}$ with DI water for 5 times to obtain $\mathrm{pH} \geq 5$ in an aqueous phase. The resulting solution was vacuum-filtered using a micropore PTFE $0.2 \mu \mathrm{m}$ filter to obtain the MXene powder. The delamination of MXene flakes was performed by hand-shaking of the sample for $5 \mathrm{~min}$, followed by centrifugation at $3500 \mathrm{rpm}$ for $1 \mathrm{~h} .{ }^{35}$ The resulting concentrated aqueous colloidal solution of $\mathrm{Ti}_{3} \mathrm{C}_{2} \mathrm{~T}_{x}$ MXene sheets was used for the doping of $1 \mathrm{~L} \mathrm{WS}_{2}$. Due to the etching process, $\mathrm{Ti}_{3} \mathrm{C}_{2}$ MXene contains fluorine elements; hence, the resulting materials will be referred to as $\mathrm{F}-\mathrm{Ti}_{3} \mathrm{C}_{2} \mathrm{~T}_{x}$ in this study. $\mathrm{N}$-doped $\mathrm{Ti}_{3} \mathrm{C}_{2} \mathrm{~T}_{x}$ was prepared using the post-annealing method. $\mathrm{F}-\mathrm{Ti}_{3} \mathrm{C}_{2} \mathrm{~T}_{x}$ was placed in a tube CVD in a $\mathrm{NH}_{3} / \mathrm{Ar}$ atmosphere at $400{ }^{\circ} \mathrm{C}$ for $4.5 \mathrm{~h}$ to obtain $\mathrm{N}-\mathrm{Ti}_{3} \mathrm{C}_{2} \mathrm{~T}_{x}$.

\subsection{Characterization}

The Raman spectra, PL spectra and mapping were conducted using a WITec alpha $300 \mathrm{R}$ system at excitation wavelengths of 488 and $532 \mathrm{~nm}$, respectively. In order to avoid heating and optical doping effect, the power of the laser was kept as low as $10 \mu \mathrm{W}$ for the room temperature PL measurement. The AFM measurement was performed using a cyphers. The crystal structure, sample size, morphologies, and surface element were determined via X-ray diffraction (XRD), transmission electron microscopy (TEM) and X-ray photoelectron spectroscopy (XPS).

\subsection{Mxene doping}

MXenes were dispersed in an isopropanol (IPA) solution at a concentration of $\sim 10 \mathrm{mg} \mathrm{mL}{ }^{-1}$. The dopant of MXenes was deposited via a drop-casting method. The volume of doping was
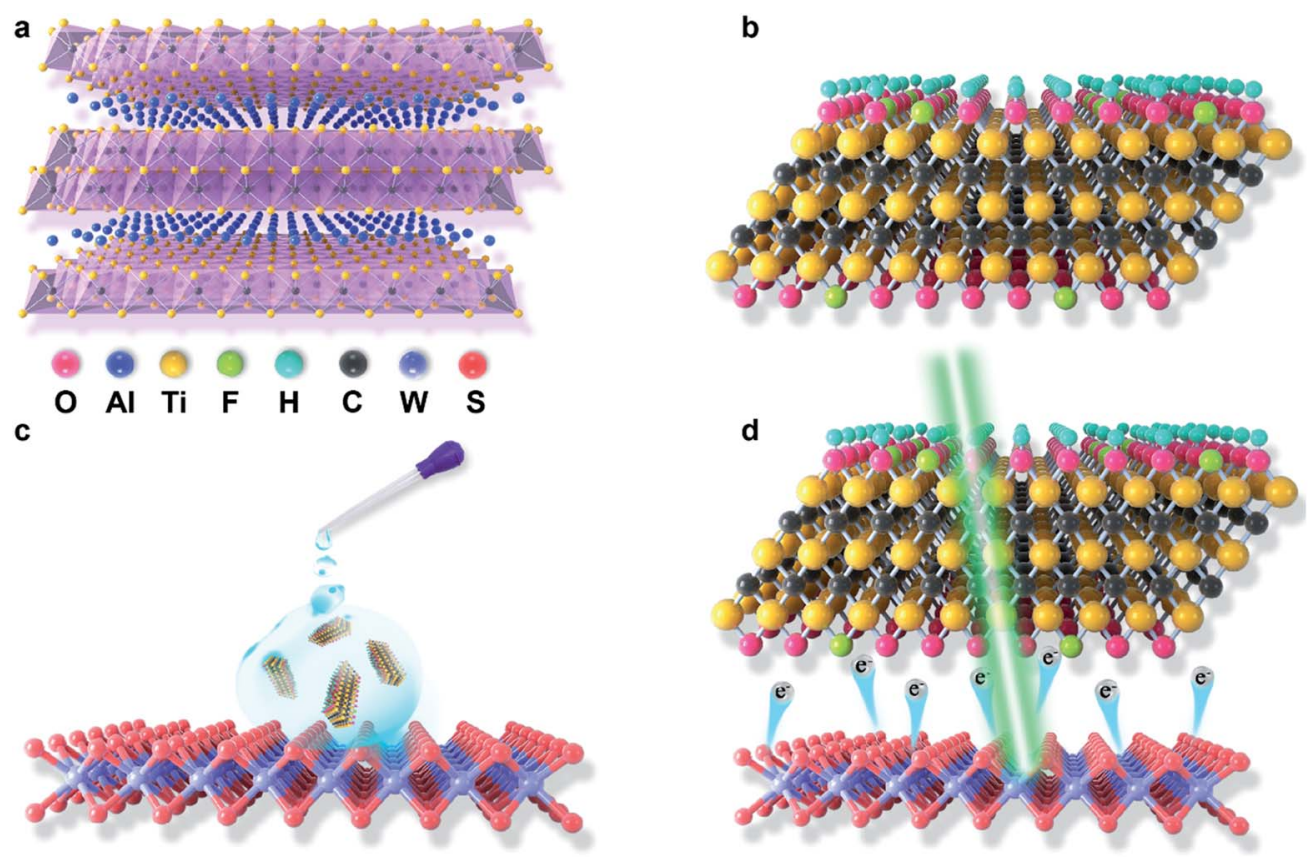

Fig. 1 Schematic of the MAX phase of $\mathrm{Ti}_{3} \mathrm{AlC}_{2}(\mathrm{a}), \mathrm{HF}$-etched and delaminated MXene $\left(\mathrm{F}-\mathrm{Ti}_{3} \mathrm{C}_{2} \mathrm{~T}_{x}\right)$ nano-flakes $(\mathrm{b}), \mathrm{F}-\mathrm{Ti}{ }_{3} \mathrm{C}_{2} \mathrm{~T}_{x}$ nano-flakes doping in $1 \mathrm{~L} \mathrm{WS_{2 }}$ via drop-coating (c) and (d) withdrawal of electrons from monolayer $\mathrm{WS}_{2}$ to $\mathrm{F}_{-}-\mathrm{Ti}_{3} \mathrm{C}_{2} \mathrm{~T}_{x}$ nano-flakes under the $532 \mathrm{~nm}$ laser excitation. 
$\sim 10 \mu \mathrm{L}$. All the measurements were performed after the sample was dried under an ambient condition.

\section{Result and discussion}

\subsection{MXene nano-flake preparation and characterization}

The MXene $\left(\mathrm{F}-\mathrm{Ti}_{3} \mathrm{C}_{2} \mathrm{~T}_{x}\right)$ nano-flakes can be conventionally prepared via a sequence of etching and delamination processes (see Experimental section). The typical morphology of MXene nano-flakes was characterized via transmission electron microscopy (TEM). As shown in Fig. 2a, the thin $\mathrm{F}_{-}-\mathrm{Ti}_{3} \mathrm{C}_{2} \mathrm{~T}_{x}$ nano-flakes are dispersed as a stack of few layers. To further characterize the quality of the exfoliated $\mathrm{F}-\mathrm{Ti}_{3} \mathrm{C}_{2} \mathrm{~T}_{x}$ nano-flakes, X-ray diffraction (XRD) and Raman spectroscopy were also performed. The XRD pattern (Fig. 2b, bottom, black line) of $\mathrm{Ti}_{3} \mathrm{AlC}_{2}$ MAX phase shows the typical (002), (004), (101), (103), (104), (105), and (107) XRD peaks at $2 \theta$ degree of $9.78^{\circ}, 19.47^{\circ}$, $34.10^{\circ}, 36.95^{\circ}, 39.30^{\circ}, 42.07^{\circ}$, and $48.88^{\circ}$, respectively, which is in accordance with previous reports. ${ }^{40}$ The disappearance of a strong (104) peak at $2 \theta=39.30^{\circ}$ demonstrates the successful preparation of $\mathrm{F}-\mathrm{Ti}_{3} \mathrm{C}_{2} \mathrm{~T}_{x}$ nano-flakes through the removal of $\mathrm{Al}$ atom (Fig. 2b, top, red line). Furthermore, the as-prepared $\mathrm{F}-$ $\mathrm{Ti}_{3} \mathrm{C}_{2} \mathrm{~T}_{x}$ nano-flakes showed a lower $2 \theta$ degree $\left(9.14^{\circ}\right)$ and a broader peak compared to that of $\mathrm{Ti}_{3} \mathrm{AlC}_{2}$, which suggests a change in the $c$-lattice parameter and decreased the structure order in $\mathrm{F}-\mathrm{Ti}_{3} \mathrm{C}_{2} \mathrm{~T}_{x}$ nano-flakes, reconfirming the successful delamination. ${ }^{\mathbf{4 1}}$ The Raman spectrum shown in Fig. 2c exhibits several vibration modes with peaks at 262.91, 403.46, 520.41 and $597.47 \mathrm{~cm}^{-1}$, which could be assigned to nonstoichiometric titanium carbides. $^{42}$ Additional peaks at 1347.58 and $1573.93 \mathrm{~cm}^{-1}$ could have originated from the D and $\mathrm{G}$ bands of carbon layers in the as-prepared $\mathrm{F}-\mathrm{Ti}_{3} \mathrm{C}_{2} \mathrm{~T}_{x}$ nano-flakes. ${ }^{42} \mathrm{X}$-ray photoelectron spectroscopy (XPS) investigations were conducted to characterize the surface chemical compositions of the asprepared $\mathrm{F}-\mathrm{Ti}_{3} \mathrm{C}_{2} \mathrm{~T}_{x}$ nano-flakes. The full-spectrum XPS (Fig. 2d) reveals several elements including titanium, carbon, oxygen and fluoride, demonstrating the presence of $-\mathrm{O},-\mathrm{F}$ and $-\mathrm{OH}$ terminations on the surface of $\mathrm{F}_{-} \mathrm{Ti}_{3} \mathrm{C}_{2} \mathrm{~T}_{x}$ nano-flakes. ${ }^{41,43}$ The high-resolution XPS spectra of $\mathrm{F}-\mathrm{Ti}_{3} \mathrm{C}_{2} \mathrm{~T}_{x}$ nano-flakes in $\mathrm{F}$ regions can be fitted using two peaks centred at 683.99 and $682.5 \mathrm{eV}$, indicating the existence of both $\mathrm{Ti}-\mathrm{F}$ and $\mathrm{Al}-\mathrm{F}$, respectively. The $\mathrm{O} 1 \mathrm{~s}$ core level can be deconvoluted into four components at 533.80, 532.91, 531.84 and $530.73 \mathrm{eV}$, which can be attributed to $\mathrm{H}_{2} \mathrm{O}$, Ti-OH, C-Ti $(\mathrm{OH})_{x}$ and $\mathrm{C}-\mathrm{Ti}-\mathrm{O}_{x}$, respectively. The XPS spectrum of Ti $2 \mathrm{p}$ (Fig. S1 $\dagger$ ) verifies the presence of $\mathrm{Ti}-\mathrm{C}, \mathrm{Ti}-\mathrm{O}$ and $\mathrm{Ti}-\mathrm{F}$, respectively. Moreover, the highresolution $\mathrm{C}$ 1s XPS spectrum shows three fitting peaks, corresponding to $\mathrm{C}-\mathrm{Ti}, \mathrm{C}-\mathrm{C}$, and $\mathrm{C}-\mathrm{O}$, respectively (Fig. $\mathrm{S} 2 \dagger$ ).

\subsection{Preparation and characterization of tungsten disulfide}

To demonstrate the exciton modulation of $1 \mathrm{~L} \mathrm{WS}_{2}$ via MXene deposition, we prepared a monolayer $\mathrm{WS}_{2}$. The standard micromechanical method was used to exfoliate $1 \mathrm{~L}-\mathrm{WS}_{2}$ from bulk crystals via a Scotch tape and transferred onto a silicon (Si) wafer with a $280 \mathrm{~nm}$ thick thermal oxidation $\left(\mathrm{SiO}_{2}\right)$ coated layer. ${ }^{44}$ The exfoliated $\mathrm{WS}_{2}$ flakes were determined by an optical microscope image, Raman spectrum, atomic force microscopy
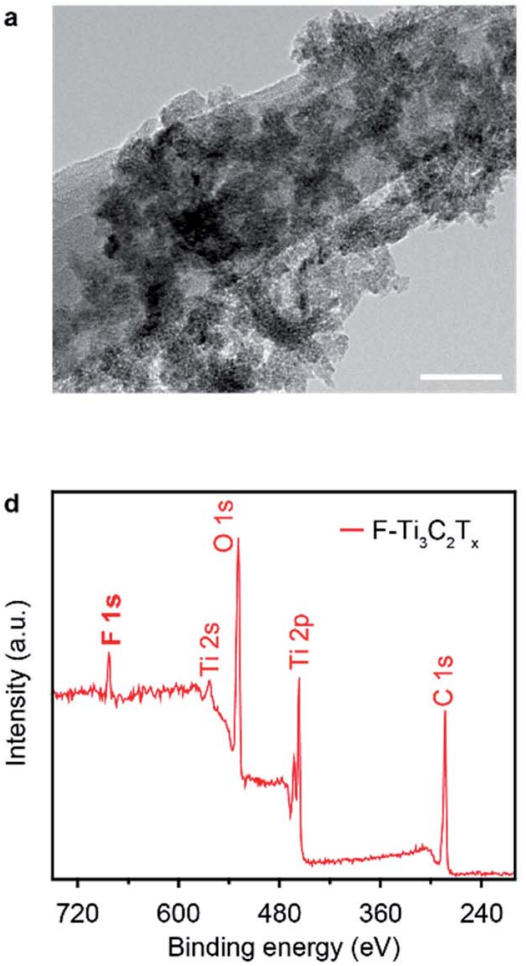
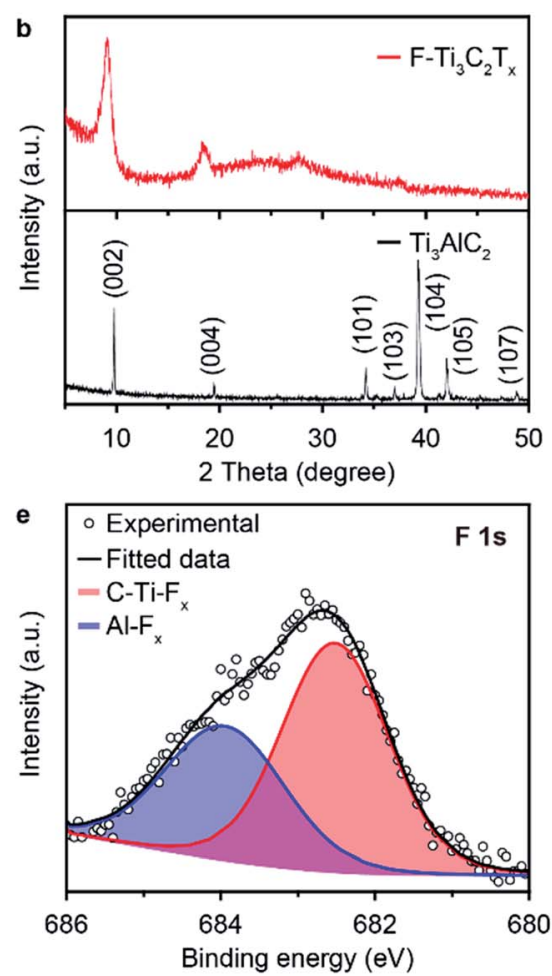
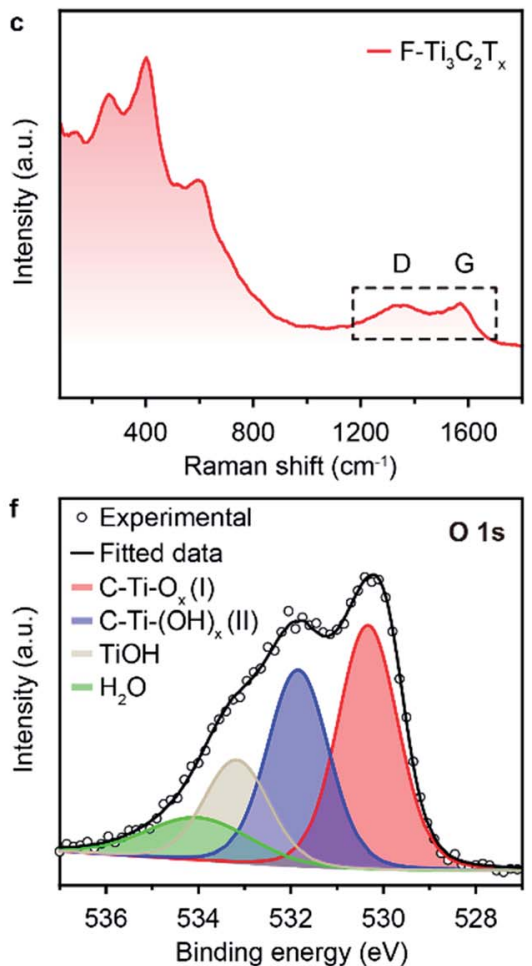

Fig. 2 (a) TEM images, (b) XRD patterns and (c) Raman spectrum of $F-T_{i} C_{2} T_{x}$ nano-flakes. (d-f) XPS spectra of $F-T i_{3} C_{2} T_{x}$ nano-flakes in (d) full spectrum region, (e) $\mathrm{F} 1 \mathrm{~s}$ region and (f) $\mathrm{O} 1 \mathrm{~s}$ region. Shaded colored areas in (e) and (f) represent curve-fitting results. The scale bar in (a) is $50 \mathrm{~nm}$. 
(AFM) and PL measurement to determine their exact layer number. The typical optical microscope image of $1 \mathrm{~L}-\mathrm{WS}_{2}$ flakes on $\mathrm{SiO}_{2} / \mathrm{Si}$ is shown in Fig. S3a. $\dagger$ The thickness of exfoliated flakes is revealed by the AFM height profile based on a noncontact mode, and measured along the white dot line crossing the flakes. The thickness of the 1-layer $\mathrm{WS}_{2}$ is about $0.8 \mathrm{~nm}$, as shown in Fig. S3b and $c, \uparrow$ in which the slight drop in the boundaries may be induced by the absorbed residues and/or molecules. The Raman spectrum (Fig. S4†) of exfoliated flake excited with a $488 \mathrm{~nm}$ laser exhibits two strong peaks at about 355 and $417 \mathrm{~cm}^{-1}$, which can be defined as in-plane $\mathrm{E}_{2 \mathrm{~g}}^{1}$ and outof-plane $\mathrm{A}_{1 \mathrm{~g}}$ vibration modes, respectively. The difference $(\Delta)$ between $\mathrm{A}_{1 \mathrm{~g}}$ and $\mathrm{E}_{2 \mathrm{~g}}^{1}$ peaks is $\sim 62.3 \mathrm{~cm}^{-1},\left(\Delta=\mathrm{A}_{1 \mathrm{~g}}-\right.$ $\mathrm{E}_{2 \mathrm{~g}}^{1}$ ), confirming the monolayer feature of the exfoliated $\mathrm{WS}_{2}$ flake. ${ }^{45}$ In addition, the PL mapping measurement was adapted to verify the monolayer characteristics of the exfoliated flakes. The bright emission of the monolayer $\mathrm{WS}_{2}$ (Fig. S5a $\dagger$ ) is observed in the dot area in Fig. S3a. $\dagger$ However, on the account of the transition from direct band gap monolayer to indirect band gap multi-layer, the PL intensity of other area in Fig. S3a† cannot be observed. ${ }^{17}$ It should be noted that the intensities of the PL mapping are slightly uneven, which may be caused by the non-uniformity natural n-doping effect in exfoliated $1 \mathrm{~L} \mathrm{WS}_{2}$.
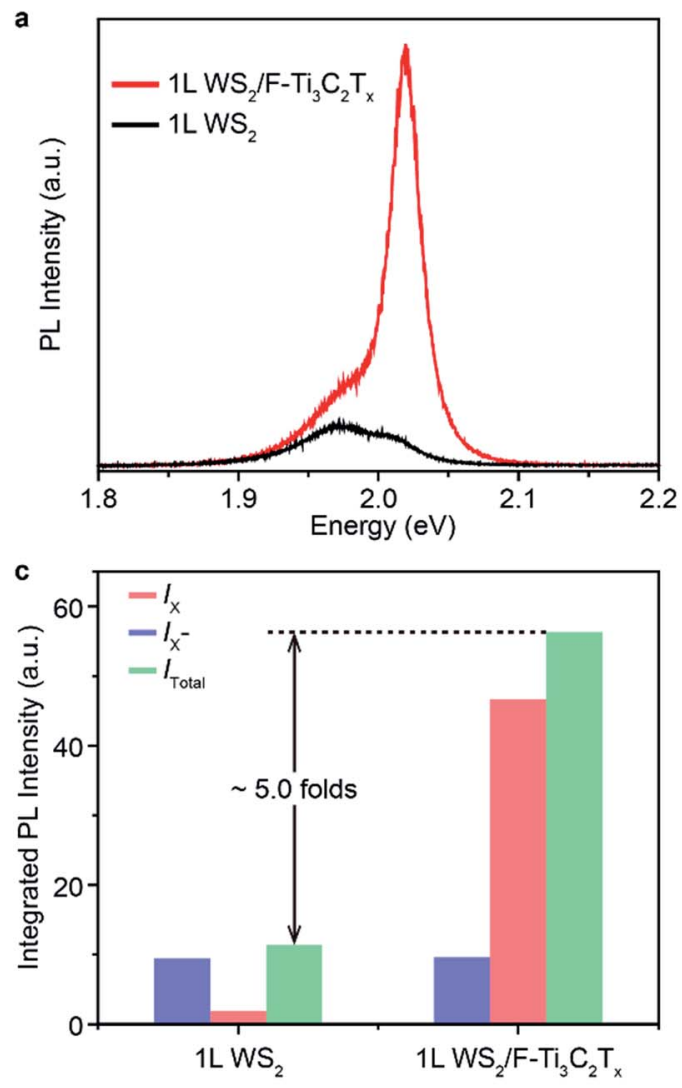

The weaker PL emission area should have a higher n-doping level compared to the higher PL intensity area, which would lead to the increased emission from low-intensity negative trions formed via the combination of excess electrons and neutral excitons (Fig. S5b $\dagger$ ) in the extracted PL spectrum. ${ }^{46}$ Moreover, the spectrum exhibits a peak at around $1.97 \mathrm{eV}$ for monolayer $\mathrm{WS}_{2}$ (Fig. S5b $\dagger$ ), which is similar to that reported previously. As the strong spin-orbit interaction induced energy difference of A and $\mathrm{B}$ excitons in the emission spectrum is as large as $\sim 0.4 \mathrm{eV}$, the emission from B exciton was not detected under a $532 \mathrm{~nm}$ laser excitation. ${ }^{47}$

\subsection{Exciton/trion modulation via MXene doping}

To test the superiority of $\mathrm{F}-\mathrm{Ti}_{3} \mathrm{C}_{2} \mathrm{~T}_{x}$ nano-flakes in controlling the carrier density of $\mathrm{WS}_{2}, \mathrm{~F}-\mathrm{Ti}_{3} \mathrm{C}_{2} \mathrm{~T}_{x}$ nano-flakes were deposited onto $1 \mathrm{~L} \mathrm{WS}_{2}$ by drop-casting. A direct evidence to indicate the successful electron modulation in $\mathrm{WS}_{2}$ is the enhanced PL emission. Pristine $\mathrm{WS}_{2}$ shows a weak PL emission with a peak centred at $\sim 1.97 \mathrm{eV}$ (Fig. 3a). The low emission intensity and relatively small peak energy could have originated from the heavy $\mathrm{n}$-doping feature in pristine $1 \mathrm{~L} \mathrm{WS}_{2} \cdot{ }^{46}$ After the coupling of $\mathrm{F}-\mathrm{Ti}_{3} \mathrm{C}_{2} \mathrm{~T}_{x}$ and $1 \mathrm{~L} \mathrm{WS}$, the PL intensity of $1 \mathrm{~L} \mathrm{WS} / \mathrm{F}-\mathrm{Ti}_{3} \mathrm{C}_{2} \mathrm{~T}_{x}$ has remarkably increased, which is almost $\sim 5.0$ folds more
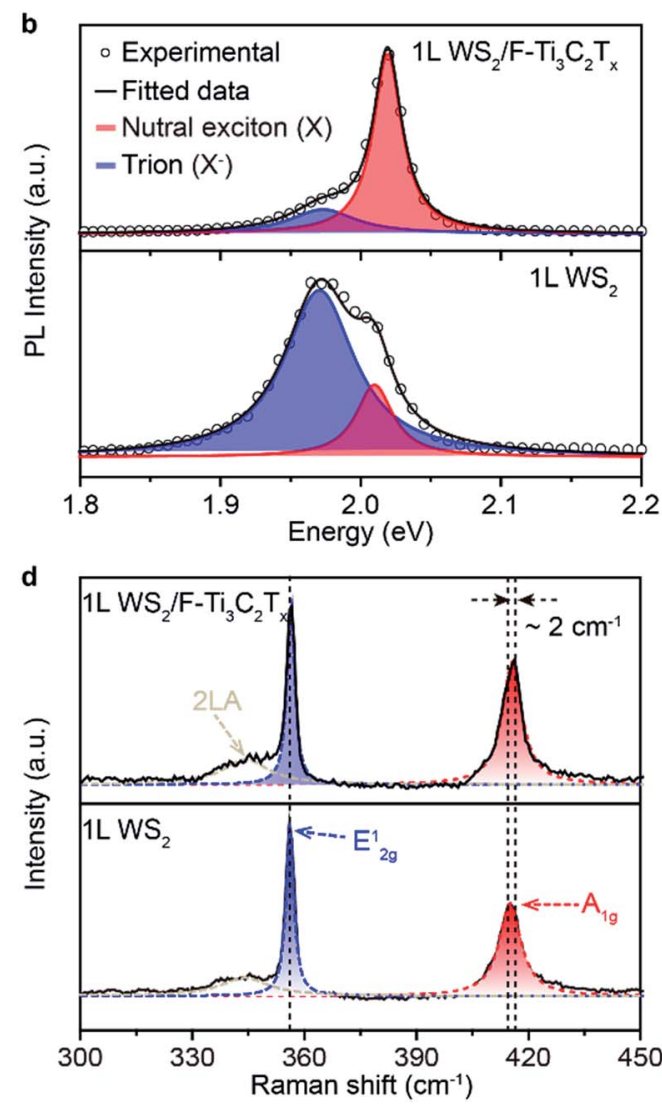

Fig. 3 (a) PL spectra of $1 L W S_{2}$ and $1 \mathrm{~L} \mathrm{WS} / F-T_{3} C_{2} T_{x}$ measured at room temperature. The doping of $F-T_{3} C_{2} T_{x}$ nano-flakes clearly modified the $\mathrm{PL}$ intensity and peak positions. (b) Fitted PL spectra of $1 \mathrm{~L} W S_{2}$ and $1 \mathrm{~L} W \mathrm{~S}_{2} / \mathrm{F}-\mathrm{Ti}_{3} \mathrm{C}_{2} \mathrm{~T}_{x}$. Note that the peaks in PL spectra were fitted using the Lorentzian fitting by assuming two peaks of the neutral exciton $(X)$ and trion $\left(X^{-}\right)$peaks. (c) The integrated PL intensity of the neutral excitons $(/ x)$,

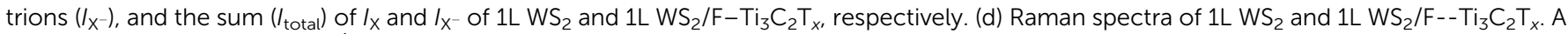
slightly blue shift by $\sim 2.0 \mathrm{~cm}^{-1}$ was observed in the $A_{1 g}$ mode of $1 \mathrm{~L} W S_{2} / F-T i_{3} C_{2} T_{x}$ compared to that of pristine $1 \mathrm{~L} W S_{2}$. 
than that of pristine $1 \mathrm{~L} \mathrm{WS}_{2}$ (Fig. 3c). Meanwhile, the peak position is also blue shifted to $\sim 2.02 \mathrm{eV}$. To clearly figure out the variation in $\mathrm{PL}$ properties caused by $\mathrm{F}-\mathrm{Ti}_{3} \mathrm{C}_{2} \mathrm{~T}_{x}$ nano-flake doping, the Lorentzian fitting was performed. The fitted results of $1 \mathrm{~L} \mathrm{WS}_{2} / \mathrm{F}-\mathrm{Ti}_{3} \mathrm{C}_{2} \mathrm{~T}_{x}$ and $1 \mathrm{~L} \mathrm{WS}_{2}$ are shown in the top and bottom panels of Fig. $3 \mathrm{~b}$, respectively. The peaks of $1 \mathrm{~L} \mathrm{WS}_{2} /$ $\mathrm{F}-\mathrm{Ti}_{3} \mathrm{C}_{2} \mathrm{~T}_{x}$ and $1 \mathrm{~L} \mathrm{WS}$ can be well fitted by assuming two peaks of neutral exciton (X) and negative trion $\left(\mathrm{X}^{-}\right)$peaks. ${ }^{25}$ According to the fitted results, the dominant peak is assigned to the negative trion with a spectral weight $\left(I_{\mathrm{X}^{-}} / I_{\text {total }}\right)$ of up to $\sim 0.82$ (Fig. $3 \mathrm{~b}$ and c). It should be noted that the neutral exciton peak becomes predominant and the weight of the negative trion of $1 \mathrm{~L}$ $\mathrm{WS}_{2} / \mathrm{F}-\mathrm{Ti}_{3} \mathrm{C}_{2} \mathrm{~T}_{x}$ is greatly decreased to $\sim 0.18$. The variation in the PL intensity and peak position could be ascribed to the transition from negative trions to neutral excitons after $\mathrm{F}$ $\mathrm{Ti}_{3} \mathrm{C}_{2} \mathrm{~T}_{x}$ nano-flake doping. The exciton transition could be well explained by the p-type doping, which can significantly decrease the electron density of $1 \mathrm{~L} \mathrm{WS}_{2} \cdot{ }^{24}$ According to the previous report, the $\mathrm{A}_{1 \mathrm{~g}}$ vibration mode of $1 \mathrm{~L} \mathrm{WS}$ Raman spectrum is very susceptible to electron coupling. The decrease in the electron density could cause blue-shifting of the $A_{1 g}$ vibration mode. ${ }^{17}$ Therefore, in order to confirm the change in the electron density in $1 \mathrm{~L} \mathrm{WS}_{2} / \mathrm{F}-\mathrm{Ti}_{3} \mathrm{C}_{2} \mathrm{~T}_{x}$, the Raman spectra of $1 \mathrm{~L} \mathrm{WS}_{2} /$ $\mathrm{F}-\mathrm{Ti}_{3} \mathrm{C}_{2} \mathrm{~T}_{x}$ was measured. As shown in Fig. 3d, the Raman spectrum of $1 \mathrm{~L} \mathrm{WS}_{2} / \mathrm{F}-\mathrm{Ti}_{3} \mathrm{C}_{2} \mathrm{~T}_{x}$ shows a blue-shifted $\mathrm{A}_{1 \mathrm{~g}}$ vibration mode of $\sim 2 \mathrm{~cm}^{-1}$, indicating the decrease in the electron density of $1 \mathrm{~L} \mathrm{WS}_{2} / \mathrm{F}-\mathrm{Ti}_{3} \mathrm{C}_{2} \mathrm{~T}_{x}$. Consequently, the variation in PL and Raman properties could originate from the withdrawal of electrons from $1 \mathrm{~L} \mathrm{WS}$ to $\mathrm{F}-\mathrm{Ti}_{3} \mathrm{C}_{2} \mathrm{~T}_{x}$ nano-flakes owing to the surface electron-withdrawing group and physically and/or chemically adsorbed $\mathrm{H}_{2} \mathrm{O}$ of $\mathrm{F}-\mathrm{Ti}_{3} \mathrm{C}_{2} \mathrm{~T}_{x}$ nano-flakes (Fig. $1 \mathrm{~b}$ and d). ${ }^{17,45}$

\subsection{Effect of surface functional group of MXenes on PL enhancement}

In order to figure out the vital role of the surface electronwithdrawing group and adsorbed $\mathrm{H}_{2} \mathrm{O}$ of MXene nano-flakes on the enhancement of the PL emission of $1 \mathrm{~L} \mathrm{WS}_{2}$, a control experiment was performed using an as-synthesized nitrogen (N)-substituted MXene $\left(\mathrm{N}-\mathrm{Ti}_{3} \mathrm{C}_{2} \mathrm{~T}_{x}\right)$ as a dopant. $\mathrm{N}-\mathrm{Ti}_{3} \mathrm{C}_{2} \mathrm{~T}_{x}$ was constructed by annealing HF-etched $\mathrm{Ti}_{3} \mathrm{C}_{2} \mathrm{~T}_{x}$ in ammonia at $700{ }^{\circ} \mathrm{C}$ and characterized by XPS and Raman spectra. ${ }^{40}$ The fullspectrum XPS reveals several elements, including titanium, carbon, oxygen and nitrogen, demonstrating the presence of $-\mathrm{O},-\mathrm{OH}$ and $-\mathrm{N}$ terminations on the surface of $\mathrm{N}-\mathrm{Ti}_{3} \mathrm{C}_{2} \mathrm{~T}_{x}$ nanoflakes (Fig. 4a). It should be noted that the strong electronwithdrawing $\mathrm{F}$ functional group was successfully eliminated at high temperatures, which would significantly decrease the electron-withdrawing ability of $\mathrm{N}-\mathrm{Ti}_{3} \mathrm{C}_{2} \mathrm{~T}_{x}$ nano-flakes. ${ }^{48}$ The high-resolution XPS spectra of the $\mathrm{N}-\mathrm{Ti}_{3} \mathrm{C}_{2} \mathrm{~T}_{x}$ nano-flakes in $\mathrm{N}$ regions can be fitted using two peaks centred at 401.45 and $399.25 \mathrm{eV}$ (Fig. 4b), indicating the existence of both $\mathrm{C}-\mathrm{N}$ and $\mathrm{Ti}-$ $\mathrm{N}$, respectively. The $\mathrm{O} 1 \mathrm{~s}$ core level can be deconvoluted into two components at 532.21 and $530.73 \mathrm{eV}$, which could be attributed to $\mathrm{C}-\mathrm{Ti}(\mathrm{OH})_{\mathrm{x}}$, and $\mathrm{C}-\mathrm{Ti}-\mathrm{O}_{x}$, respectively (Fig. 4c). This demonstrates the removal of physically and/or chemically adsorbed $\mathrm{H}_{2} \mathrm{O}$ at high temperatures, suggesting a further decrease in the electron-withdrawing ability of $\mathrm{N}-\mathrm{Ti}_{3} \mathrm{C}_{2} \mathrm{~T}_{x}$ nano-flakes. The Raman spectrum of $\mathrm{N}-\mathrm{Ti}_{3} \mathrm{C}_{2} \mathrm{~T}_{x}$ nano-flakes is similar to that of $\mathrm{F}-\mathrm{Ti}_{3} \mathrm{C}_{2} \mathrm{~T}_{x}$ nano-flakes owing to the preserved $\mathrm{Ti}_{3} \mathrm{C}_{2}$ structure
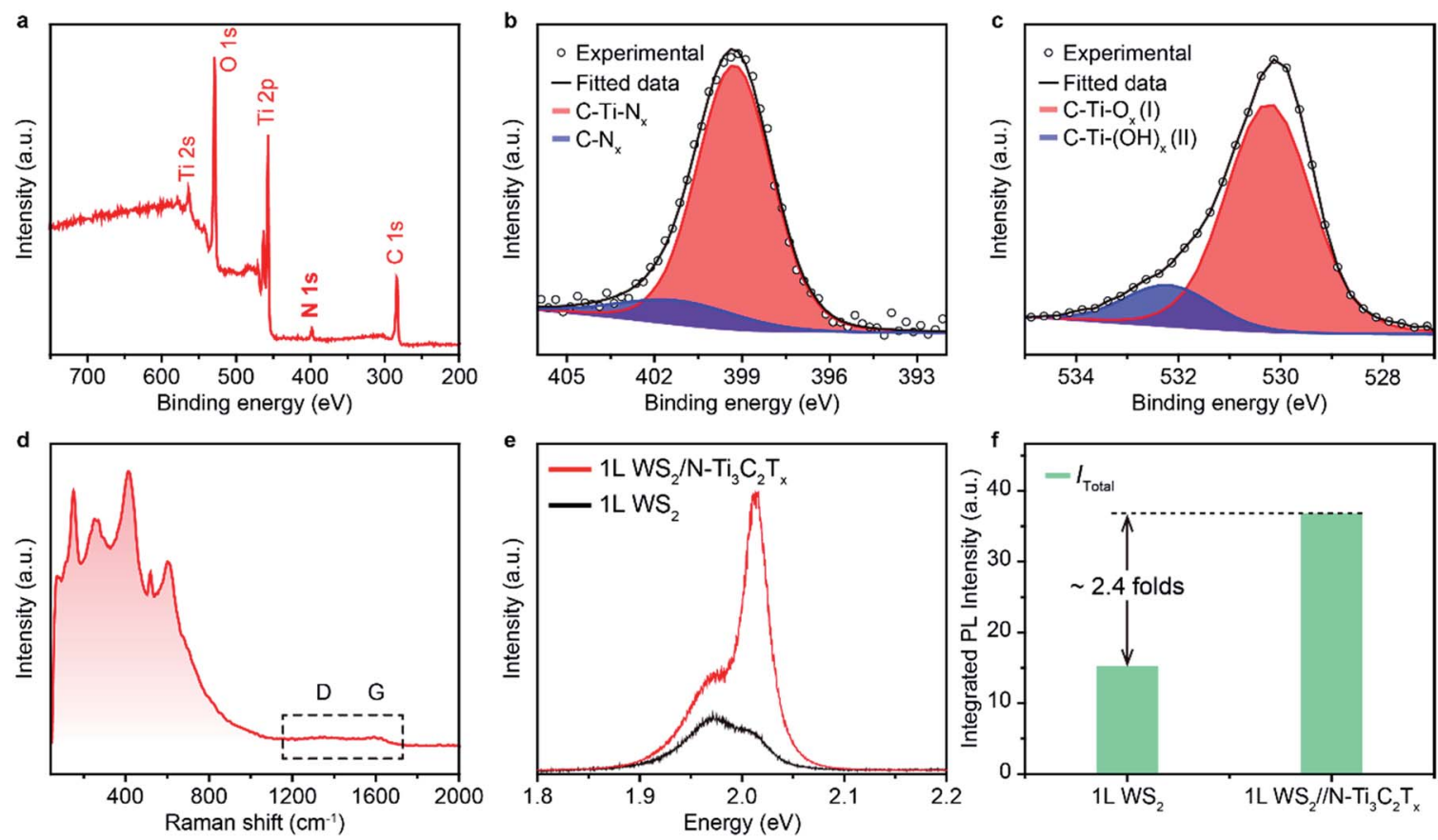

Fig. 4 (a-c) X-ray photoelectron (XPS) spectra of $\mathrm{F}-\mathrm{Ti}_{3} \mathrm{C}_{2} \mathrm{~T}_{x}$ nano-flakes in (a) full-spectrum region, (b) $\mathrm{N} 1 \mathrm{~s}$ region and (c) $\mathrm{O} 1 \mathrm{~s}$ region. Shaded colored areas in (b) and (c) represent curve-fitting results. (d) Raman spectrum of $\mathrm{N}-\mathrm{Ti}_{3} \mathrm{C}_{2} \mathrm{~T}_{x}$ nano-flakes. (e) PL spectra of $1 \mathrm{~L} W S_{2}$ and $1 \mathrm{~L} W S_{2} / \mathrm{N}-$ $\mathrm{Ti}_{3} \mathrm{C}_{2} \mathrm{~T}_{x}$ measured at room temperature. (f) The integrated total (Itotal) PL intensity of $1 \mathrm{~L} W S_{2}$ and $1 \mathrm{~L} W S_{2} / F-\mathrm{Ti}_{3} \mathrm{C}_{2} \mathrm{~T}_{x}$. 
(Fig. 4d). It is worth noting that the $\mathrm{D}$ and $\mathrm{G}$ bands almost disappear, indicating the disordered carbon sheets of $\mathrm{N}$ $\mathrm{Ti}_{3} \mathrm{C}_{2} \mathrm{~T}_{x}$ nano-flakes induced by the $\mathrm{N}$-intercalation. To verify the evolution of the PL emission of $1 \mathrm{~L} \mathrm{WS}$ via $\mathrm{N}-\mathrm{Ti}_{3} \mathrm{C}_{2} \mathrm{~T}_{x}$ nanoflake doping, the $\mathrm{PL}$ spectrum of $1 \mathrm{~L} \mathrm{WS}_{2} / \mathrm{N}-\mathrm{Ti}_{3} \mathrm{C}_{2} \mathrm{~T}_{x}$ was measured. As shown in Fig. 4e, although $1 \mathrm{~L} \mathrm{WS} / \mathrm{N}-\mathrm{Ti}_{3} \mathrm{C}_{2} \mathrm{~T}_{x}$ also shows an improved PL emission with an exciton transition from negative trion to neutral exciton, the PL enhancement is much lower ( $\sim 2.41$ folds) compared to that of $1 \mathrm{~L} \mathrm{WS}_{2} / \mathrm{F}-\mathrm{Ti}_{3} \mathrm{C}_{2} \mathrm{~T}_{x}$ (Fig. 4f). The decreased PL enhancement of $1 \mathrm{~L} \mathrm{WS}_{2} / \mathrm{N}-\mathrm{Ti}_{3} \mathrm{C}_{2} \mathrm{~T}_{x}$ could be attributed to the decreased charge transfer from $1 \mathrm{~L}$ $\mathrm{WS}_{2}$ to $\mathrm{N}-\mathrm{Ti}_{3} \mathrm{C}_{2} \mathrm{~T}_{x}$ owing to the elimination of a strong electronwithdrawing functional group of $\mathrm{F}$ and adsorbed $\mathrm{H}_{2} \mathrm{O}{ }^{17,45}$

\section{Conclusions}

In summary, we succeeded in achieving the p-type doping of $1 \mathrm{~L}$ $\mathrm{WS}_{2}$ via surface functional group-modified MXene nano-flakes. Upon doping with MXene nano-flakes, the blue-shifted $\mathrm{A}_{1 \mathrm{~g}}$ vibration mode and enhanced PL efficiency of neutral excitons can be obviously observed. These findings can serve as a direct proof of the regulated optoelectronic properties of $1 \mathrm{~L} \mathrm{WS}_{2}$, demonstrating that the p-doping effect is dominant in surface functional group-modified MXene nano-flake-doped $1 \mathrm{~L}-\mathrm{WS}_{2}$. The modulation of the optoelectronic properties of $1 \mathrm{~L} \mathrm{WS}_{2}$ by drop-coating with MXene nano-flakes could be ascribed to the effective charge transfer from $1 \mathrm{~L} \mathrm{WS}_{2}$ to MXenes induced by strong electron-withdrawing characteristics inherited from the surface fluorine functional group and/or adsorbed $\mathrm{H}_{2} \mathrm{O}$ presented on the MXene nano-flakes. In addition, the electronwithdrawing ability of MXenes can be facilely controlled by tuning the type of surface functional groups. These findings suggest that 2D MXenes are promising materials for regulating the optical and electronic properties of $1 \mathrm{~L}-\mathrm{WS}_{2}$, offering a new avenue to construct new heterostructure junctions, such as high-performance photodetectors, ambipolar transport field effect transistors, and flexible solar energy harvesting devices, and broadening the horizon for harnessing the unique properties of MXenes.

\section{Conflicts of interest}

There are no conflicts to declare.

\section{Acknowledgements}

This work is supported by SERC (Grant No. 1426500050) from the Agency for Science, Technology and Research (A*STAR), Singapore National Research Foundation, Competitive Research Program (Grant No. NRF-CRP18-2017-02), Singapore Ministry of Education Tier 2 Program (Grant No. MOE2016-T21-128) and National Natural Science Foundation of China (Grant No. 61704082) and Natural Science Foundation of Jiangsu Province (Grant No. BK20170851). H. Li would like to thank the support from Nanyang Technological University under NAP award (M408050000) and Singapore Ministry of Education Tier 1 program (2018-T1-001-051).

\section{Notes and references}

1 M. Amani, D. H. Lien, D. Kiriya, J. Xiao, A. Azcatl, J. Noh, S. R. Madhvapathy, R. Addou, S. KC, M. Dubey, K. Cho, R. M. Wallace, S. C. Lee, J. H. He, J. W. Ager, X. Zhang, E. Yablonovitch and A. Javey, Science, 2015, 350, 1065-1068.

2 W. Choi, N. Choudhary, G. H. Han, J. Park, D. Akinwande and Y. H. Lee, Mater. Today, 2017, 20, 116-130.

3 S. Manzeli, D. Ovchinnikov, D. Pasquier, O. V. Yazyev and A. Kis, Nat. Rev. Mater., 2017, 2, 17033.

4 X. Yu, P. Yu, D. Wu, B. Singh, Q. Zeng, H. Lin, W. Zhou, J. Lin, K. Suenaga, Z. Liu and Q. J. Wang, Nat. Commun., 2018, 9, 1545.

5 X. Duan, C. Wang, A. Pan, R. Yu and X. Duan, Chem. Soc. Rev., 2015, 44, 8859-8876.

6 C. L. Tan and H. Zhang, Chem. Soc. Rev., 2015, 44, 2713-2731. 7 J. Pu and T. Takenobu, Adv. Mater., 2018, 30, 1707627.

8 S. C. Dhanabalan, J. S. Ponraj, Z. Guo, S. Li, Q. Bao and H. Zhang, Adv. Sci., 2017, 4, 1600305.

9 S. Wang, A. Robertson and J. H. Warner, Chem. Soc. Rev., 2018, 47, 6764-6794.

10 J. S. Ross, S. Wu, H. Yu, N. J. Ghimire, A. M. Jones, G. Aivazian, J. Yan, D. G. Mandrus, D. Xiao, W. Yao and X. Xu, Nat. Commun., 2013, 4, 1474.

11 Y. Zhang, C. Lim, Z. Dai, G. Yu, J. W. Haus, H. Zhang and P. N. Prasad, Phys. Rep., 2019, 795, 1-51.

12 L. J. Li, E. C. O'Farrell, K. P. Loh, G. Eda, B. Ozyilmaz and N. A. Castro, Nature, 2016, 529, 185-189.

13 J. Pei, J. Yang, X. Wang, F. Wang, S. Mokkapati, T. Lü, J. Zheng, Q. Qin, D. Neshev, H. H. Tan, C. Jagadish and Y. Lu, ACS Nano, 2017, 11, 7468-7475.

14 J. D. Lin, C. Han, F. Wang, R. Wang, D. Xiang, S. Qin, X. Zhang, L. Wang, H. Zhang, A. T. S. Wee and W. Chen, ACS Nano, 2014, 8, 5323-5329.

15 J. Pei, J. Yang, T. Yildirim, H. Zhang and Y. Lu, Adv. Mater., 2019, 31, 1706945.

16 Z. Hu, Z. Wu, C. Han, J. He, Z. Ni and W. Chen, Chem. Soc. Rev., 2018, 47, 3100-3128.

17 N. Peimyoo, W. Yang, J. Shang, X. Shen, Y. Wang and T. Yu, ACS Nano, 2014, 8, 11320-11329.

18 X. Chen and A. R. McDonald, Adv. Mater., 2016, 28, 57385746.

19 S. Zhang, H. M. Hill, K. Moudgil, C. A. Richter, A. R. Hight Walker, S. Barlow, S. R. Marder, C. A. Hacker and S. J. Pookpanratana, Adv. Mater., 2018, 30, 1802991.

20 C. Cong, J. Shang, Y. Wang and T. Yu, Adv. Opt. Mater., 2016, 6, 1700767.

21 Z. Wang, Z. Dong, Y. Gu, Y. Chang, L. Zhang, L. Li, W. Zhao, G. Eda, W. Zhang, G. Grinblat, S. A. Maier, J. K. W. Yang, C. Qiu and A. T. S. Wee, Nat. Commun., 2016, 7, 11283.

22 Y. I. Jhon, Y. Kim, J. Park, J. H. Kim, T. Lee, M. Seo and Y. M. Jhon, Adv. Funct. Mater., 2016, 26, 7551-7559.

23 Y. Sun, Z. Zhou, Z. Huang, J. Wu, L. Zhou, Y. Cheng, J. Liu, C. Zhu, M. Yu, P. Yu, W. Zhu, Y. Liu, J. Zhou, B. Liu, H. Xie, Y. Cao, H. Li, X. Wang, K. Liu, X. Wang, J. Wang, L. Wang and W. Huang, Adv. Mater., 2019, 31, 1806562. 
24 C. R. Ryder, J. D. Wood, S. A. Wells and M. C. Hersam, ACS Nano, 2016, 10, 3900-3917.

25 S. Mouri, Y. Miyauchi and K. Matsuda, Nano Lett., 2013, 13, 5944-5948.

26 Y. Tao, X. Yu, J. Li, H. Liang, Y. Zhang, W. Huang and Q. J. Wang, Nanoscale, 2018, 10, 6294-6299.

27 M. Ghidiu, M. R. Lukatskaya, M. Zhao, Y. Gogotsi and M. W. Barsoum, Nature, 2014, 516, 78-171.

28 M. Naguib, V. N. Mochalin, M. W. Barsoum and Y. Gogotsi, Adv. Mater., 2014, 26, 992-1005.

29 H. Lin, Y. Chen and J. Shi, Adv. Sci., 2018, 5, 1800518.

30 M. Hu, T. Hu, Z. Li, Y. Yang, R. Cheng, J. Yang, C. Cui and X. Wang, ACS Nano, 2018, 12, 3578-3586.

31 J. Liu, H. Zhang, R. Sun, Y. Liu, Z. Liu, A. Zhou and Z. Yu, Adv. Mater., 2017, 29, 1702367.

32 X. Jiang, S. Liu, W. Liang, S. Luo, Z. He, Y. Ge, H. Wang, R. Cao, F. Zhang, Q. Wen, J. Li, Q. Bao, D. Fan and H. Zhang, Laser Photonics Rev., 2018, 12, 1700229.

33 L. Wu, X. Jiang, J. Zhao, W. Liang, Z. Li, W. Huang, Z. Lin, Y. Wang, F. Zhang, S. Lu, Y. Xiang, S. Xu, J. Li and H. Zhang, Laser Photonics Rev., 2018, 12, 1800215.

34 M. Naguib, J. Come, B. Dyatkin, V. Presser, P. Taberna, P. Simon, M. W. Barsoum and Y. Gogotsi, Electrochem. Commun., 2012, 16, 61-64.

35 S. Chertopalov and V. N. Mochalin, ACS Nano, 2018, 12, 6109-6116.

36 B. Anasori, M. R. Lukatskaya and Y. Gogotsi, Nat. Rev. Mater., 2017, 2, 16098.
37 C. Xing, S. Chen, X. Liang, Q. Liu, M. Qu, Q. Zou, J. Li, H. Tan, L. Liu, D. Fan and H. Zhang, ACS Appl. Mater. Interfaces, 2018, 10, 27631-27643.

38 L. Ding, Y. Wei, Y. Wang, H. Chen, J. Caro and H. Wang, Angew. Chem., Int. Ed., 2017, 56, 1825-1829.

39 Y. Liu, H. Xiao and W. A. Goddard, J. Am. Chem. Soc., 2016, 138, 15853-15856.

40 Y. Wen, T. E. Rufford, X. Chen, N. Li, M. Lyu, L. Dai and L. Wang, Nano Energy, 2017, 38, 368-376.

$41 \mathrm{~S} . \mathrm{Tu}, \mathrm{Q}$. Jiang, X. Zhang and H. N. Alshareef, ACS Nano, 2018, 12, 3369-3377.

42 K. Krishnamoorthy, P. Pazhamalai, S. Sahoo and S. Kim, J. Mater. Chem. A, 2017, 5, 5726-5736.

43 S. J. Kim, H. Koh, C. E. Ren, O. Kwon, K. Maleski, S. Cho, B. Anasori, C. Kim, Y. Choi, J. Kim, Y. Gogotsi and H. Jung, ACS Nano, 2018, 12, 986-993.

44 X. Yu, S. Zhang, H. Zeng and Q. J. Wang, Nano Energy, 2016, 25, 34-41.

45 H. M. Oh, H. Jeong, G. H. Han, H. Kim, J. H. Kim, S. Y. Lee, S. Y. Jeong, S. Jeong, D. J. Park, K. K. Kim, Y. H. Lee and M. S. Jeong, ACS Nano, 2016, 10, 10446-10453.

46 P. K. Chow, R. B. Jacobs-Gedrim, J. Gao, T. Lu, B. Yu, H. Terrones and N. Koratkar, ACS Nano, 2015, 9, 1520-1527.

47 B. Zhu, H. Zeng, J. Dai and X. Cui, Adv. Mater., 2014, 26, 5504-5507.

48 S. Lai, J. Jeon, S. K. Jang, J. Xu, Y. J. Choi, J. Park, E. Hwang and S. Lee, Nanoscale, 2015, 7, 19390-19396. 